\title{
Preparation and Flame-retardant Mechanism of Flame- retardant Air Filter Paper
}

\author{
Yan Li, ${ }^{a}$ Lizheng Sha, ${ }^{\mathrm{a}, *}$ Huifang Zhao, ${ }^{\mathrm{a}}$ and Cheng Huang ${ }^{\mathrm{b}}$ \\ Four flame retardants and styrene-acrylic latex were used to make \\ flame-retardant air filter paper via emulsion impregnation. The \\ compositions and flame retardant mechanism of the flame retardants \\ were investigated by using scanning electron microscopy (SEM), Fourier \\ transform infrared spectroscopy (FTIR), and thermogravimetric analysis \\ (TGA). The flame retardance of air filter paper was evaluated using TGA \\ and limiting oxygen index (LOI) meter, and the physical properties and \\ pore structure of the flame-retardant air filter paper were measured using \\ stiffness tester, burst tester, and aperture analyzer. The results showed \\ that the optimal ratio of flame retardant to styrene-acrylic latex was 1:1.4. \\ The synergistic effect of boron, phosphorus and nitrogen made FR3 \\ have good flame-retardant effect on air filter paper. Air filter paper with \\ FR3 also had good physical strength and suitable pore size distribution.
}

Keywords: Flame retardant; Styrene-acrylic latex; Air filter paper; Physical properties; Flame-retardant properties

Contact information: a: Zhejiang University of Science \& Technology, Hangzhou, 310023, Zhejiang, China; b: Hangzhou Special Paper Co., Ltd., Hangzhou, 310023, Zhejiang, China;

* Corresponding author: slz9966@163.com

\section{INTRODUCTION}

The engine is generally considered the "heart" of an automobile, and the air filter is an important part of the engine, which acts to remove dust and other impurities before they can enter the engine cylinder and acts to reduce the wear of the cylinder block and piston ring, thus extending the service life of the engine. Automotive air filter paper is the core component of an air filter and called as the "lung" of an air filter. The main components of the commonly used air filter paper are flammable cellulose fiber and latex, and this composition may result in the combustion of air filter paper when an engine backfire occurs. Therefore, automobile air filter paper requires not only a good filtration effect, but also a good flame-retardant performance. With the increasing requirements of automobile safety, traditional air filter paper cannot meet the requirements of an automobile engine filter, and it must be treated to obtain flame retardant properties.

Various methods and flame retardants can improve the flame-retardant property of cellulosic paper (Shen et al. 2011; Xu et al. 2018). The production methods of flameretardant paper are classified into two types: one is to add flame retardants to pulp or paper directly (additive flame retardants), and the other is to introduce flame-retardant groups on paper fibers through chemical reactions (reactive flame retardants). The addition methods consist of slurry-added, dipping, coating, and size-pressing. Most of the current methods are dipping and coating for the flame retardant treatment of paper and paper products (Hebeish et al. 1999). The dipping method can control the basis weight of the paper well, and the processing time is short and the operation is convenient (Hebeish 
et al. 1999). Some flame retardants can be directly added to pulp to prepare flameretardant paper, such as metal oxides, metal hydroxides, boron compounds, and silicon compounds (Si and Guo 2016). The reactive flame retardant includes halogen-containing flame retardant, nitrogen-containing flame retardant and phosphorus-containing flame retardant. Halogen-containing flame retardants have not been used due to environmental problems and human health hazards. Nitrogen and phosphorus-containing synergistic flame retardants are widely used for their high flame retardant efficiency, low toxicity and low smoke release (Jia et al. 2017).

Air filter base paper is mainly made of natural flammable plant fibers, with almost no filler and chemicals. It is poor in fire resistance and water resistance, and low in strength, so it cannot meet the requirements of the automotive air filter. In order to improve the strength and fire resistance of filter paper, the base paper must be postprocessed $(\mathrm{Wu} 2011 \mathrm{a})$. At present, the main post-processing method is emulsion impregnation (Wu 2011b), and air filter paper can obtain excellent tensile strength and bursting strength after emulsion impregnation (Yuan et al. 2004; Liu et al. 2007). The emulsion or resin commonly used includes styrene-acrylic latex, polyvinyl acetate emulsion, polyacrylate emulsion, epoxy resin, phenolic resin, acrylic resin, and ureaformaldehyde resin (Caturla et al. 1999; Wang and Lin 2000; Lin and Wang 2001; Wang and Shieh 2001; Alkan et al. 2005; Tartaglione et al. 2008; Hapuarachchi and Peiji 2010). The flame-retardant latex prepared by mixing the latex and the flame retardants can disperse the flame retardants, and it imparts certain flame-retardant properties to the paper and improves the physical strength of the paper (Zhang et al. 2007; Zhou et al. 2009; Yang et al. 2010a, 2010b; Ma et al. 2017). It was reported that the flame-retardant property and physical properties of air filter paper varied with the types of flame retardants and latexes, and changed with the ratio of latex to flame retardant (Hong 2012). However, less attention has been given to the influence mechanism of flame retardants and latex on air filter paper. Moreover, the method in choosing efficient flame retardants is still a problem that puzzles those involved with air filter paper production.

In this paper, four different flame retardants and styrene-acrylic latex were used to prepare flame retardant air filter paper via impregnation. The flame retardant mechanism was revealed by components and properties analysis of the flame retardants, with a scanning electron microscopy (SEM) with a Phenom ProX, a Fourier transform infrared spectrometer (FTIR), a thermogravimetric analyzer (TGA), and a limiting oxygen index (LOI) meter. The physical strength of the air filter paper was tested using a stiffness tester and a burst tester, and the pore structure of the paper was measured using an aperture analyzer. The relationships between physical properties of the air filter paper and latex composition were explored by adjusting the ratio of latex to flame retardants, and the best flame retardant was selected under the premise of good physical strength, flame retardant property, and suitable filtration performance. The research results provide an important reference for the selection of flame retardants and the production of flameretardant air filter paper.

\section{EXPERIMENTAL}

\section{Materials}

Air filter base paper was supplied by Hangzhou Special Paper Co., Ltd., Hangzhou, China, which has a grammage of $114 \mathrm{~g} / \mathrm{m}^{2}$, a stiffness of $1.33 \mathrm{mN} . \mathrm{m}$, and 
bursting strength of $84.7 \mathrm{kPa}$. The solid content of styrene-acrylic latex was 50\%, which was purchased from BASF SE, Shanghai, China. The first flame retardant (FR1) was a melamine-treated ammonium polyphosphate (APP-II), with a particle size of $12 \mu \mathrm{m}$, a degree of polymerization (DP) $\geq 1000$ and was purchased from Presafer (Qingyuan) Phosphor Chemical Co., Ltd., Qingyuan, China. The main component of the second flame retardant (FR2) was a hydrophobically modified APP, with a particle size of 20 $\mu \mathrm{m}, \mathrm{DP} \geq 1000$, and was purchased from Qingdao Shengtang New Material Technology Co., Ltd., Qingdao, China. The third flame retardant (FR3) was a complex flame retardant containing APP-II, with a particle size of $15 \mu \mathrm{m}, \mathrm{DP} \geq 1000$, and was purchased from Shandong Xiucheng Chemical Co., Ltd., Jinan, China. The fourth flame retardant (FR4) was also a complex flame retardant, with a particle size of $15 \mu \mathrm{m}$, and was purchased from Nantong Yszr Fire-Retardant Material Co., Ltd., Nantong, China.

\section{Methods}

Water solubility of flame retardants

A total of $5 \mathrm{~g}$ of each flame retardant was added to a beaker containing $100 \mathrm{~mL}$ deionized water. Each sample was placed on a constant temperature magnetic stirrer at room temperature for $40 \mathrm{~min}$, at a stirring rate of $400 \mathrm{r} / \mathrm{min}$. After evenly dispersing the sample, $25 \mathrm{~mL}$ of liquid was centrifuged for $30 \mathrm{~min}$ at a speed of $2000 \mathrm{r} / \mathrm{min}$. Then, the supernatant liquid was removed and placed in a constant weight weighing bottle, and the mass was weighed using an analytical balance (YP-B2003, Shanghai Guangzheng Medical Instrument Co., Ltd., Shanghai, China). Finally, the sample was placed in a constant temperature oven at $110{ }^{\circ} \mathrm{C}$ for $3 \mathrm{~h}$ to obtain the quality of the flame retardant (Mo et al. 2016), thereby calculating the water solubility of the flame retardant.

\section{Preparation and performance analysis}

The flame retardants and styrene-acrylic latex were mixed at the ratio of 1:1, 1:1.2, $1: 1.4$, and 1:1.6, respectively. Then a certain amount of deionized water was added to obtain a mixed latex with a concentration of $7 \%$. The air filter base paper was immersed in the mixed solution of different ratio of FRs and styrene-acrylic latex for 2 min, and the impregnation increment was controlled at $22 \pm 2 \%$, and then the wet paper were dried in a constant temperature oven at $105^{\circ} \mathrm{C}$.

\section{Characterization}

The structure and elemental composition of the flame retardants were determined via scanning electron microscopy (SEM) with a Phenom ProX (Thermo Fisher Scientific, Eindhoven, Netherlands). The sample was examined after vacuum coated with a thin layer of gold using a plasma sputtering coater (SBC-12, Chengdu Zhongke Weishi Instrument Co., Ltd., Chengdu, China).

Fourier transform infrared (FTIR) spectra were collected using a spectrometer (VERTEX 70 IR, Bruker Optik GmbH, Ettlingen, Germany). The samples were ground into powder and then blended with $\mathrm{KBr}$, and then the mixture was pressed into ultra-thin pellets, and then scanned at room temperature over a wavenumber range from 500 to $4000 \mathrm{~cm}^{-1}$. The resolution ratio of the FTIR spectrometer was $4 \mathrm{~cm}^{-1}$.

Thermogravimetric analysis (TGA) was performed using a thermogravimetric analyzer (STA 449 F3, NETZSCH-Gerätebau GmbH, Selb, Germany). The samples were heated from room temperature to $900.0^{\circ} \mathrm{C}$ at a heating rate of $10.0^{\circ} \mathrm{C} / \mathrm{min}$ in a nitrogen atmosphere. 
The flammability of the samples was measured on a limiting oxygen index meter (JF-3, Nanjing Jiong Lei Instrument Equipment Co., Ltd., Nanjing, China). The dimensions of the specimens for the test were approximately length was $100 \mathrm{~mm}$ and width was $10 \mathrm{~mm}$.

The stiffness and bursting strength of the flame-retardant air filter paper were measured using a stiffness tester (WTD-1000, Hangzhou Qingtong Boke Automation Technology Co., Ltd., Hangzhou, China) and a burst tester (PN-BSM160, Hangzhou Pinxiang Technology Co., Ltd., Hangzhou, China).

The pore size distribution of the flame retardant air filter paper were measured using an aperture analyzer (PSDA-20; Nanjing Gaoqian Functional Materials Technology Co., Ltd., Nanjing, China). The paper sample was cut into a circle in a diameter of $30 \mathrm{~mm}$ and was sucked in a vacuum wetting apparatus at $-0.07 \sim-0.08 \mathrm{MPa}$. Then the sample was sealed between two sealing rings and pressed tightly. The pressure valve was adjusted to 0.6 MPa during the test, with a starting air intake of $200 \mathrm{~mL}$.

\section{RESULTS AND DISCUSSION}

\section{SEM Analysis and Chemical Composition}

The surface morphology of the different flame retardants are shown in Fig. 1, and Table 1 reports their chemical compositions.
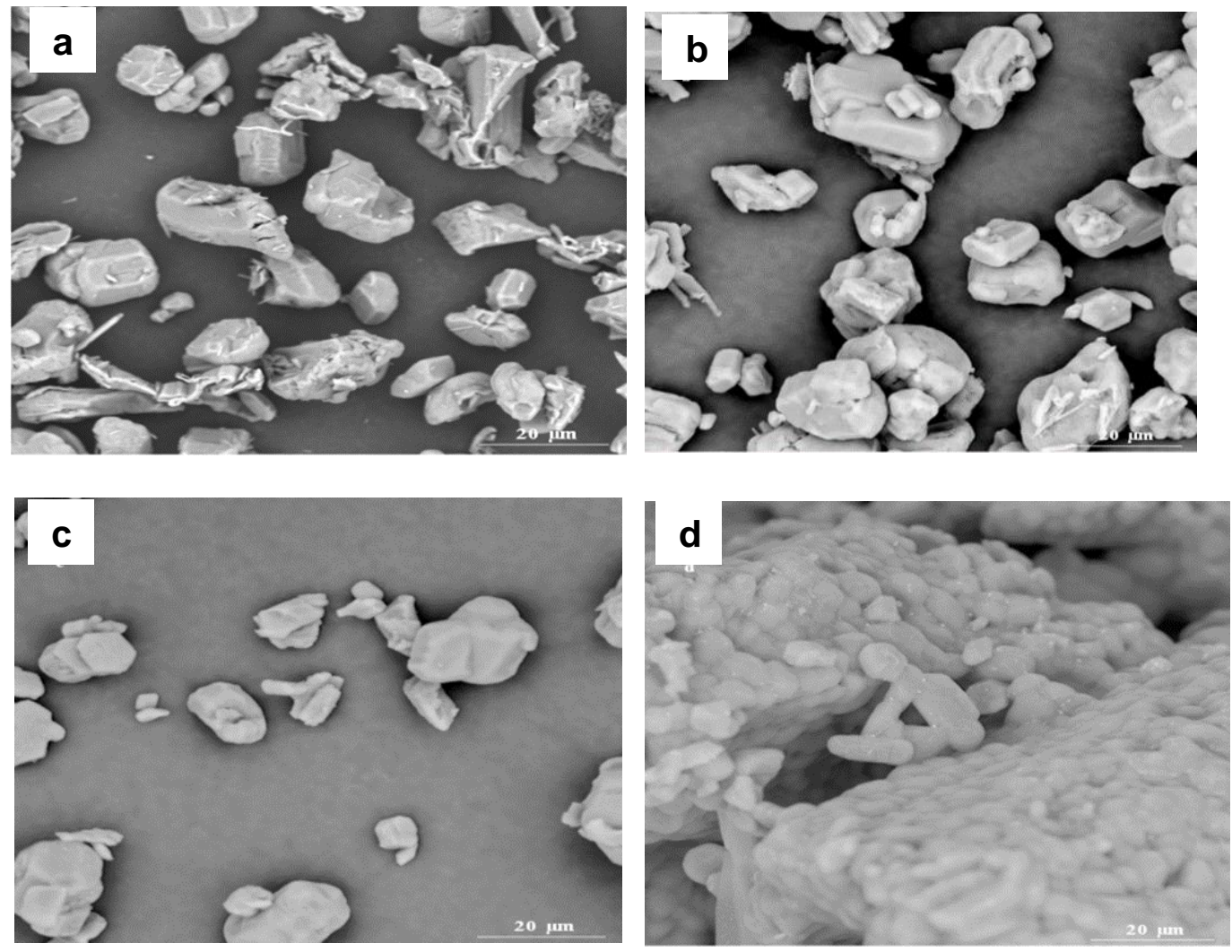

Fig. 1. Morphology and chemical composition of FR1 (a), FR2 (b), FR3 (c), FR4 (d); the magnification times were $3000 \times$ 
Table 1. Chemical Composition of FRs

\begin{tabular}{|c|c|c|c|c|}
\hline \multirow{2}{*}{ Element Symbol } & \multicolumn{4}{|c|}{ Element content (\%) } \\
\cline { 2 - 5 } & FR1 & FR2 & FR3 & FR4 \\
\hline C & 26.3 & 30.0 & 51.5 & 15.3 \\
\hline O & 41.6 & 42.0 & 15.9 & 34.9 \\
\hline N & 26.4 & 22.5 & 11.5 & 44.4 \\
\hline P & 5.4 & 5.2 & 0.9 & 5.1 \\
\hline B & - & - & 20.2 & - \\
\hline Y & 0.4 & 0.3 & - & 0.3 \\
\hline
\end{tabular}

As shown in Fig. 1, the FR1, FR2, and FR3 were in the form of fine particles, and the FR4 was a lump formed by the bonding of rod-shaped particles. There was some coating on the surface of the FR1 and FR2 particles. The chemical composition results show that the main elements of FR1, FR2 and FR4 were $\mathrm{C}, \mathrm{O}, \mathrm{N}$, and $\mathrm{P}$, and for FR3 the main constituents were $\mathrm{C}, \mathrm{O}, \mathrm{N}$ and $\mathrm{B}$, whereas there was very little $\mathrm{P}$ in FR3. FR3 contained a lot of element B. Therefore, it was concluded that the flame retardants FR1, FR2, and FR4 were N, P-based flame retardants and FR3 was a N, B-based flame retardant. It was found from the element ratio of the four flame retardants that FR1 and FR2 almost had the same ratio of N/P, but the ratio of N/P in FR3 and FR4 were higher than that of FR1 and FR2. It implied that the chemical components of FR3 and FR4 were greatly different.

\section{FTIR Analysis}

The FTIR spectra of the four different flame retardants are shown in Fig. 2. The spectra showed some peaks at 3215, 1242, 1068, and $1006 \mathrm{~cm}^{-1}$. The peak at $3215 \mathrm{~cm}^{-1}$ is assigned to $\mathrm{N}-\mathrm{H}$ stretching vibration absorption, the peak at $1242 \mathrm{~cm}^{-1}$ corresponds to the vibration absorption of $\mathrm{PO}$, the peak at $1068 \mathrm{~cm}^{-1}$ is ascribed to $\mathrm{P}-\mathrm{N}$ stretching vibration, and the peak at $1006 \mathrm{~cm}^{-1}$ is assigned to P-O-P stretching vibrations ( $\mathrm{Xu}$ et al. 2018). Comparing the FTIR spectra and the characteristic absorption peaks of the above flame retardants, a small characteristic peak located at $800 \mathrm{~cm}^{-1}$ and $682 \mathrm{~cm}^{-1}$ was found, but there were no noticeable peaks at $602 \mathrm{~cm}^{-1}$ and $760 \mathrm{~cm}^{-1}$ in FR1, FR2, and FR3, and all characteristic absorption peaks of FR1, FR2, and FR3 appeared in the same position.

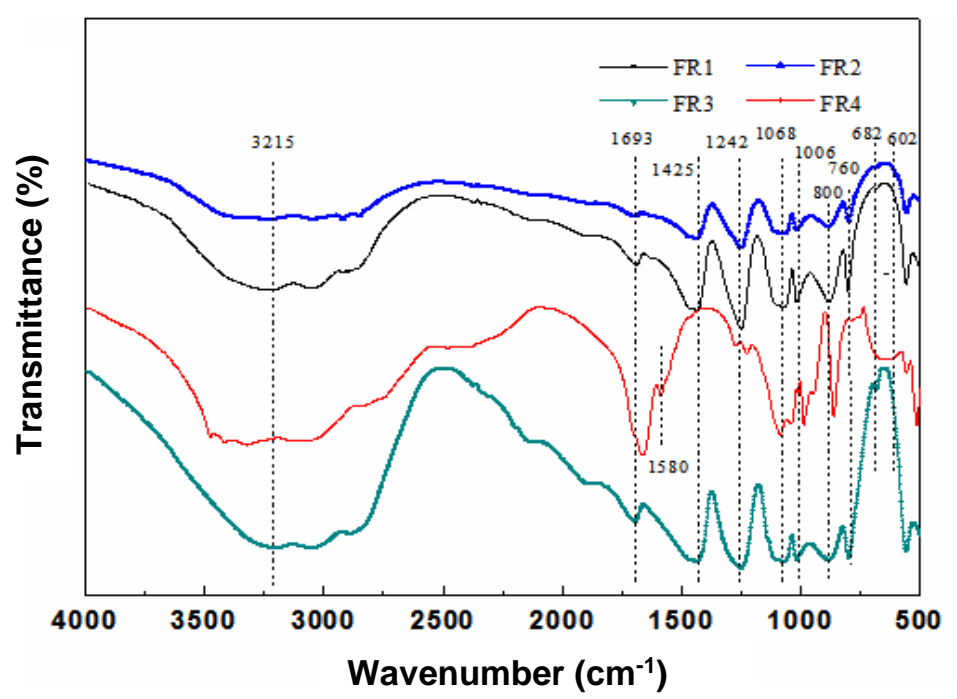

Fig. 2. FTIR spectra of different flame retardants 
It has been reported that in the FTIR spectrum, I-APP (I-type ammonium polyphosphate) has strong absorption peaks near $760 \mathrm{~cm}^{-1}, 682 \mathrm{~cm}^{-1}$, and $602 \mathrm{~cm}^{-1}$, while II-APP does not. Both have an absorption peak at $800 \mathrm{~cm}^{-1}$ and the absorption peak is independent of the crystal structure; therefore, the intensity ratio of the peak $\left(682 \mathrm{~cm}^{-}\right.$ $1 / 800 \mathrm{~cm}^{-1}$ ) had a good linear relationship with the content of I-APP in the sample (Sun et al. 2004). It was determined that FR1, FR2, and FR3 all contained a certain amount of APP and the main crystal form was II-APP; however, the FR1, FR2 and FR3 also contained a certain amount of I-APP. The FTIR spectra of FR4 was quite different from the others: two obvious peaks occurred at $1650 \mathrm{~cm}^{-1}$ and $1580 \mathrm{~cm}^{-1}$, which could be assigned to $\mathrm{C}=\mathrm{N}$ stretching vibration absorption and $\mathrm{N}-\mathrm{H}$ bending vibration absorption, indicating that FR4 was mainly a guanidine compound (Zhang et al. 1999).

\section{Water-solubility Analysis}

Table 2 shows that FR4 had high water solubility, while the other three FRs had low water solubility and were greatly insoluble in water. FR1 and FR2 were APP modified with melamine and hydrophobic agent, so they had low water solubility. The water solubility of FR3 was higher than FR1 and FR2 due to their high content of boron compound. Combined with elemental analysis and infrared analysis results, it can be inferred that FR4 might be a guanidine dihydrogen phosphate, so its water solubility was larger than that of the other three FRs.

Table 2. Water Solubility of FRs (\%)

\begin{tabular}{|c|c|c|c|}
\hline FR1 & FR2 & FR3 & FR4 \\
\hline 0.262 & 0.242 & 0.477 & 5.810 \\
\hline
\end{tabular}

\section{Thermogravimetric Analysis of FRs}

The TGA curves of flame retardants obtained in a nitrogen atmosphere are shown

in Fig. 3 and Table 3 lists the relevant thermal decomposition data.
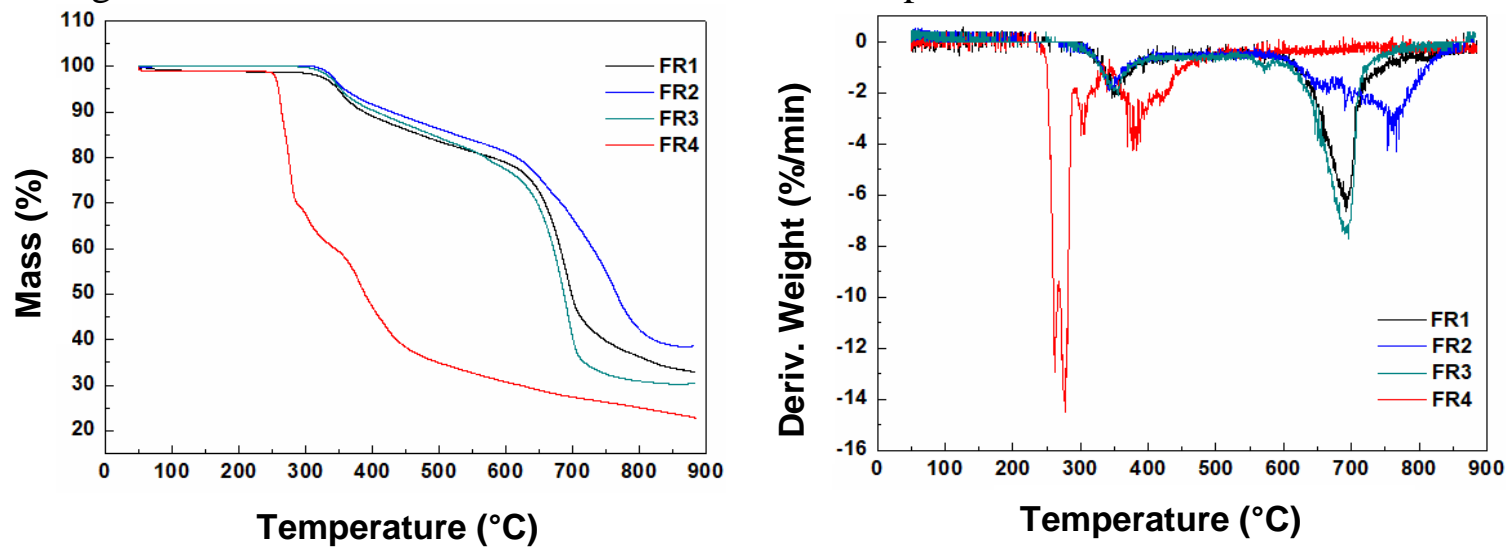

Fig. 3. TG (a) and DTG (b) curves of flame retardants

Table 3. TG Data of Different FRs

\begin{tabular}{|c|c|c|c|}
\hline Sample & $T_{\mathrm{d}}\left({ }^{\circ} \mathrm{C}\right)$ & $T_{\max }\left({ }^{\circ} \mathrm{C}\right)$ & Residues at $880{ }^{\circ} \mathrm{C}(\%)$ \\
\hline FR1 & 273.6 & 692.8 & 35.3 \\
\hline FR2 & 272.1 & 766.2 & 41.1 \\
\hline$F R 3$ & 275.2 & 695.3 & 33.0 \\
\hline FR4 & 235.1 & 277.7 & 25.3 \\
\hline
\end{tabular}

$T_{\mathrm{d}}$ - initial degradation temperature; $T_{\max }$ - maximum mass loss temperature 
The FR1, FR2, and FR3 had similar TG curves, indicating that the main components of the three flame retardants were basically the same, which was similar to that of APP. There were two main mass loss steps for FR1, FR2, and FR3. The first step appeared at the temperature range of 280 to $620^{\circ} \mathrm{C}$, and the mass loss was mostly due to the release of $\mathrm{NH}_{3}$ and $\mathrm{H}_{2} \mathrm{O}$ and the crosslinking of $\mathrm{P}-\mathrm{OH}$ to form polyphosphoric acid (Camino et al. 1985). The second step occurred at the temperature range of 620 to $750{ }^{\circ} \mathrm{C}$, which could be attributed to the release of phosphoric acid, polyphosphoric acid, and meta phosphoric acid ( $\mathrm{Gu}$ et al. 2007). The $T_{\mathrm{d}}$ and $T_{\max }$ of FR4 were respectively 235.1 ${ }^{\circ} \mathrm{C}$ and $277.7{ }^{\circ} \mathrm{C}$, which were far below than that of the other flame retardants, so it had the worst thermal stability, and this was consistent with the assumption that FR4 is a guanidine compound. Comparing the residues at $880{ }^{\circ} \mathrm{C}$, the residue of $\mathrm{FR} 2$ was the largest one, up to $41.1 \%$, and the residue of FR4 was the lowest one, indicating that the FR2 was better retained and a dense carbon layer was formed after high temperature combustion, that is, FR2 had the best thermal stability.

\section{Physical Properties of Flame-retardant Air Filter Paper}

The stiffness and bursting strength of the paper with FRs at different ratio of FRs and styrene-acrylic latex are depicted in Fig. 4, where the impregnation increment was 22 $\pm 2 \%$.
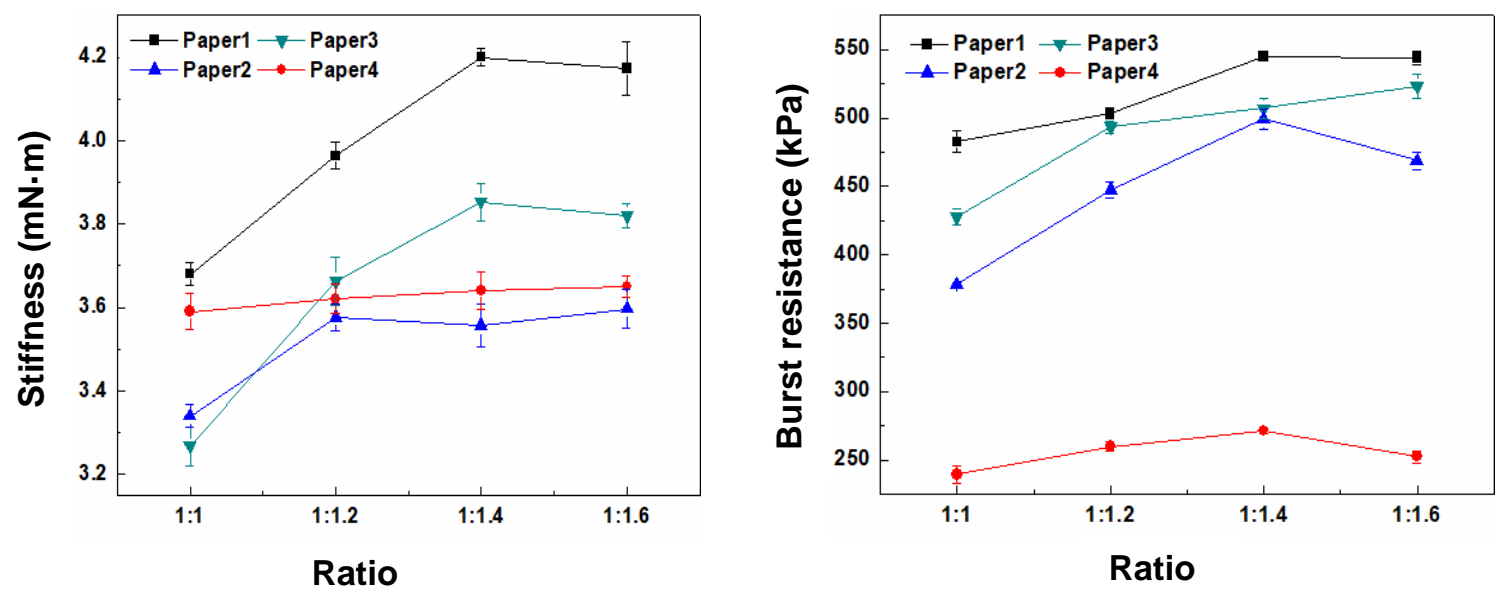

Fig. 4. The stiffness and bursting strength of paper with different FRs

Styrene-acrylic latex plays an important role in improving the strength of air filter paper. It was found that the stiffness and bursting strength of the air filter paper increased with the increase of styrene-acrylic latex content. However, the increase in stiffness and bursting strength tended to slow down, and the stiffness for Paper1 and Paper3 and bursting strength for Paper1, Paper2, and Paper4 began to decrease when the ratio of flame retardant to styrene-acrylic latex was greater than 1:1.4. Excessive increase of styrene-acrylic latex implies reductions in the proportions of flame retardants and has adverse effect on the flame retardant performance, so the optimal ratio of flame retardant to styrene-acrylic latex was $1: 1.4$. In addition, it can also be seen that the stiffness and bursting strength of paper with FR1 and FR3 were higher than that of paper with FR2 and FR4 at this ratio. For paper with FR1 and FR3, the stiffness increased by $202 \%$ and $189 \%$, and the bursting strength increased by $543 \%$ and $495 \%$, respectively. 


\section{Pore Size Distribution of Air Filter Paper}

The pore size distribution of paper with FRs were shown in Fig. 5 and Table 4. It can be seen that the maximum pore size and average pore size of Paper3 were larger than that of paper with other FRs. If a flame retardant has small particle size, good water solubility and better compatibility, it is easy to disperse in styrene-acrylic latex and form a uniform mixed flame retardant emulsion, which will fill the void between paper fibers well and decrease the pore size of the paper. Paper1 had relatively smaller average pore size due to the small particle size of FR 1 and Paper4 had smaller average pore size due to the higher water solubility of FR4. FR1 and FR2 were both modified APP, and modification made them more compatible with styrene-acrylic latex, therefore, Paper2 had a small average pore size although the particle size of FR2 was relatively large. For air filter paper, small pore size means high filtration resistance and high filtration efficiency, as well as high energy consumption. The pore size distribution of all four papers could meet the filtration efficiency requirements of air filter paper, however, the filtration resistance and the power consumption of Paper3 was the lowest one.
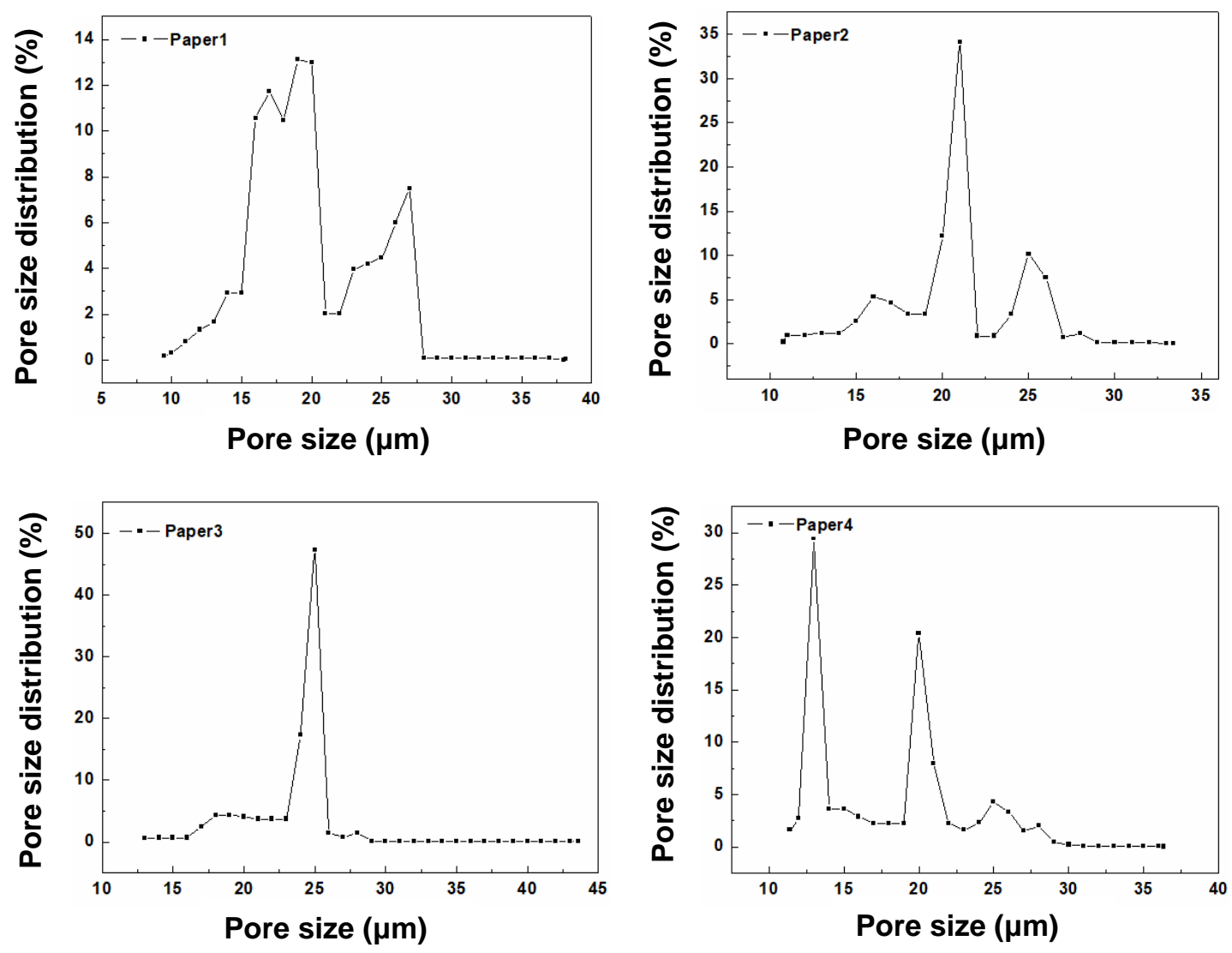

Fig. 5. Pore size distribution of paper with FRs 
Table 4. Pore Size Distribution of Air Filter Paper

\begin{tabular}{|c|c|c|c|c|}
\hline Items & Paper 1 & Paper 2 & Paper 3 & Paper 4 \\
\hline Maximum pore size $(\mu \mathrm{m})$ & 38.1 & 33.4 & 43.6 & 36.3 \\
\hline Average pore size $(\mu \mathrm{m})$ & 19.4 & 21.1 & 25.0 & 18.5 \\
\hline
\end{tabular}

\section{Flame Retardance of Air Filter Paper}

Flame retardant air filter papers were prepared by emulsion impregnation at the ratio of flame retardant to styrene-acrylic latex which was 1:1.4. Their TG data and LOI values are shown Fig. 6, Table 5, and Table 6.
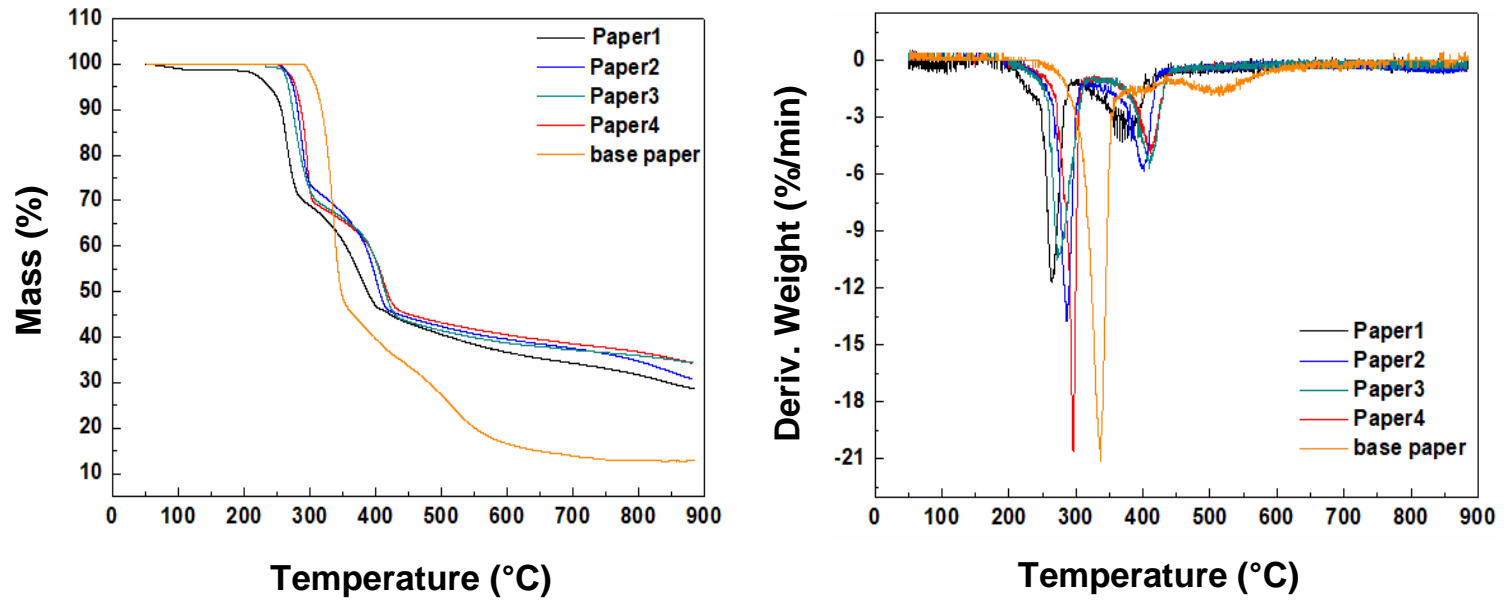

Fig. 6. TG (a) and DTG (b) curves of paper

Table 5. TG Data of Paper with Different Flame Retardants

\begin{tabular}{|c|c|c|c|}
\hline Sample & $T_{\mathrm{d}}\left({ }^{\circ} \mathrm{C}\right)$ & $T_{\max }\left({ }^{\circ} \mathrm{C}\right)$ & Residues at $880{ }^{\circ} \mathrm{C}(\%)$ \\
\hline Base paper & 290.9 & 337.2 & 12.9 \\
\hline Paper1 & 213.4 & 262.9 & 28.6 \\
\hline Paper2 & 250.6 & 286.2 & 30.7 \\
\hline Paper3 & 252.8 & 276.1 & 34.4 \\
\hline Paper4 & 247.9 & 295.2 & 34.3 \\
\hline
\end{tabular}

Figure 6 and Table 5 indicate that the thermal degradation of base paper began at $290.9^{\circ} \mathrm{C}$, and the residue at $880{ }^{\circ} \mathrm{C}$ was only $12.9 \%$, which was far below the paper with FRs. The thermal degradation of cellulose and the mass loss of base paper mainly occurred at $290{ }^{\circ} \mathrm{C} \sim 360{ }^{\circ} \mathrm{C}$. At $360{ }^{\circ} \mathrm{C} \sim 450{ }^{\circ} \mathrm{C}$ and $450{ }^{\circ} \mathrm{C} \sim 550{ }^{\circ} \mathrm{C}$ slow carbonization and oxidation occurred. For the flame retardant papers, the $T_{d}$ and the $T_{\max }$ decreased remarkably, but the residue increased significantly, which meant that the addition of flame retardant promoted the initial dehydration, prolonged carbonization of cellulose, and reduced the production of volatile combustible materials. For the flame retardant papers, the mass loss of at $220{ }^{\circ} \mathrm{C}$ to $430{ }^{\circ} \mathrm{C}$ can be attributed to the dehydration of cellulose and the release of $\mathrm{NH}_{3}$ and $\mathrm{H}_{2} \mathrm{O}$ from FRs. After $430{ }^{\circ} \mathrm{C}$, the mass loss rate of flame retardant papers slowed down because the FRs contain $\mathrm{N}$ and $\mathrm{P}$ formed phosphoric acid, which can promote the carbonization of paper and cut off the spread of heat and flame. The residue of Paper4 was 34.3\%, near to that of Paper3 and higher than Paper1 and Paper2, indicating that paper impregnated with FR3 and FR4 had better thermal stability. The TG analysis results of the paper were not consistent with the TG analysis results of the FRs, and this resulted from the different composition and different flame 
retardant mechanisms of FRs. Paper3 had good thermal stability due to its high content of boron compound, which played an important role in flame retardant. A boron compound formed a glassy substance and covered the surface of the paper when it was heated. In addition, it cut off the spread of oxygen and heat and promoted carbonization of the cellulose fiber. The boron compound had an obvious synergistic effect with APP and played a flame-retardant role in condensed phase. For paper with FR4, its good thermal stability might be a result from the flame retardation of guanidine dihydrogen phosphate, which released a lot of $\mathrm{N}_{2}, \mathrm{CO}_{2}$, and $\mathrm{NH}_{3}$ when it was heated, thereby cutting off the supply of oxygen. This produced a good gas phase flame retardant effect.

Table 6. LOI Values of Flame-retardant Papers

\begin{tabular}{|c|c|c|c|c|c|}
\hline Sample & Base paper & Paper 1 & Paper 2 & Paper 3 & Paper 4 \\
\hline LOI (\%) & 19.3 & 31.1 & 30.2 & 43.6 & 28.4 \\
\hline
\end{tabular}

The LOI value is usually used to assess the flame retardant effect of textile and paper. Table 6 shows that the LOI value of base paper was only 19.3\%, which meant that base paper was a very flammable material. After flame retardant treatment, the LOI value of air filter paper increased significantly and was able to meet the requirement of flame retardant (LOI $\geq 25 \%$ ). Paper with FR3 had higher LOI value than paper with FR1, FR2 and FR4, that is, FR3 had the best flame retardant effect. After comprehensive consideration, paper with FR3 was not only good at flame retardant property but also good at physical strength and filtration performance, so we can assume that FR3 was more suitable for preparing flame-retardant air filter paper.

\section{CONCLUSIONS}

In order to improve the physical strength and flame retardant property of automobile air filter paper, four flame retardants and styrene-acrylic latex were used to prepare flame retardant emulsion, and flame retardant air filter paper was prepared via emulsion impregnation. The experiment results showed that the physical strength of air filter paper occurred as the ratio of flame retardant to styrene-acrylic latex was 1:1.4. FR3 contain a certain amount of APP and boron compound, and the synergistic effect of boron, phosphorus and nitrogen produced a good flame-retardant effect on air filter paper. The flame-retardant air filter paper with FR3 also had excellent physical strength

and suitable pore structure, so FR3 was most suitable for preparing flame-retardant air filter paper.

\section{ACKNOWLEDGEMENTS}

This work was supported by Zhejiang provincial key technology innovation special project (2017023) and Hangzhou Special Paper Co., Ltd.

\section{REFERENCES CITED}

Alkan, M., Tekin, G., and Namli, H. (2005). "FTIR and zeta potential measurements of 
sepiolite treated with some organosilanes," Journal of Microporous and Mesoporous Materials 84(1-3), 75-83. DOI: 10.1016/j.micromeso.2005.05.016

Caturla, F., Molina-Sabio, M., and Rodriguez-Reinosof, F. (1999). “Adsorptiondesorption of water vapor by natural and heat-treated sepiolite in ambient air," Journal of Applied Clay Science 15(3-4), 367-380. DOI: 10.1016/S01691317(99)00030-7

Camino, G., Costa, L., and Trossarelli, L. (1985). "Study of the mechanism of intumescence in fire retardant polymers: Part V-Mechanism of formation of gaseous products in the thermal degradation of ammonium polyphosphate," Polymer Degradation and Stability 12(3), 203-211. DOI: 10.1016/0141-3910(85)90089-8

Gu, J.W., Zhang, G.C., Dong, S.L., Zhang Q.Y., Kong, J. (2007). "Study on preparation and fire-retardant mechanism analysis of intumescent flame-retardant coatings," Surface \& Coatings Technology 201(18), 7835-7841. DOI:

10.1016/j.surfcoat.2007.03.020

Hapuarachchi, T. D., and Peijs, T. (2010). "Multi-walled carbon nanotubes and sepiolite nanoclays as flame retardants for polylactide and its nature fibre reinforced composites," Journal of Composites Part A: Applied Science and Manufacturing 41(8), 954-963. DOI: 10.1016/j.compositesa.2010.03.004

Hebeish, A., Waly, A., and Abou-Okeil, A. M. (1999). "Flame retardant cotton," Journal of Fire and Materials 23(3), 117-123. DOI: 10.1002/(SICI)1099-

1018(199905/06)23:3<117::AID-FAM675>3.0.CO;2-Y

Hong, L. (2012). Preparation of Flame-retardant Air Filter Paper with Phosphorus and Nitrogen Flame Retardants, Master's Thesis, South China University of Technology, Guangdong, China.

Jia, Y., Lu, Y., Zhang, G., Liang, Y., and Zhang, F. (2017). "Facile synthesis of an ecofriendly nitrogen-phosphorus ammonium salt to enhance durability and flame retardancy of cotton," Journal of Materials Chemistry A 5(20), 9970-9981. DOI: 10.1039/c7ta01106g

Lin, C. H., and Wang, C. S. (2001). "Novel phosphorus-containing epoxy resins - Part I. Synthesis and properties," Journal of Applied Polymer Science 42(5), 1869-1878. DOI: 10.1016/S0032-3861(00)00447-X

Liu, W., Shi, S., and Li, J. (2007). "Effect of styrene-acrylate emulsion on filter paper fiber in automobile industry," Journal of Transactions of China Pulp and Paper 22(4), 68-70. DOI: 10.3321/j.issn:1000-6842.2007.04.017

Ma, S., Zhang, M., and Yang, B. (2017). "Research progress on flame retardant properties of automotive engine air filter paper," Journal of China Pulp \& Paper Industry 38(16), 29-36. DOI: 10.3969/j.issn.1007-9211.2017.16.006

Mo, Z., Zhao, H., Wu, C., Wu, Y., and Li, D. (2016). "'Study on preparation of flame retardant paper by microencapsulated ammonium polyphosphate with melamine formaldehyde resin," Journal of Paper and Papermaking 35(7), 35-38. DOI: 10.13472/j.ppm.2016.07.008

Shen, J., Song, Z., Qian, X., and Ni, Y. (2011). "A review on use of fillers in cellulosic paper for functional applications," Journal of Industrial \& Engineering Chemistry Research 50(2), 661-666. DOI: 10.1021/ie1021078

Si, Y., and Guo, Z. (2016). "Eco-friendly functionalized superhydrophobic recycled paper with enhanced flame-retardancy," Journal of Colloid and Interface Science 477, 74-82. DOI: 10.1016/j.jcis.2016.05.044

Sun, C., Luo, J., and Su, X. (2004). "Determination of crystal structure of ammonium 
phosphate by infrared spectroscopy," Journal of Northeast Forestry University 32(1), 94-95. DOI: 10.3969/j.issn.1000-5382.2004.01.029

Tartaglione, G., Tabuani, D., Camino, G., and Moisio, M. (2008). "PP and PBT composites filled with sepiolite: Morphology and thermal behavior," Journal of Composites Science Technology 68(2), 451-460. DOI:

10.1016/j.compscitech.2007.06.023

Wang, C. S., and Lin, C. H. (2000). "Novel phosphorus-containing epoxy resins - Part II: Curing kinetics," Journal of Applied Polymer Science 41(24), 8579-8586. DOI: 10.1016/S0032-3861(00)00211-1

Wang, C. S., and Shieh, J. Y. (2001). "Phosphorus-containing dihydric phenol or naphthol-advanced epoxy resin or cured," U.S. Patent No. 6291626B1.

$\mathrm{Wu}, \mathrm{A}$. (2011a). "Comparative analysis and discussion on the effect of curing filter paper before and after coating," Journal of East China Pulp \& Paper Industry 42(5), 21-24. DOI: 10.3969/j.issn.1674-6937.2011.05.020

Wu, A. (2011b). "Effect of filter paper raw materials on performance of filter paper," Journal of East China Pulp \& Paper Industry 42(2). DOI: 10.3969/j.issn.16746937.2011.02.009

Xu, F., Zhong, L., Xu, Y., Feng, S., Zhang, C., Zhang, F., and Zhang, G. (2018). "Highly efficient flame-retardant kraft paper,” Journal of Materials Science 54(2), 1884-1897. DOI: $10.1007 / \mathrm{s} 10853-018-2911-2$

Yang, J., Liang, Y., and Huang, C. (2010a). "Study on flame retardancy of air filter paper for internal combustion engines," Journal of China Pulp \& Paper Industry 31(22), 30-34. DOI: 10.3969/j.issn.1007-9211.2010.22.006

Yang, J., Liang, Y., Xu, G., and Hu, J. (2010b). "Preparation of the fire-retardant air filter paper for internal combustion engine," Journal of China Pulp \& Paper 29(6), 6-9. DOI: 10.3969/j.issn.0254-508X.2010.06.002

Yuan, S. J., Huang, Z. B., and Zhang, G. Y. (2004). "Application of latex in papermaking," Journal of Hu Bei Zao Zhi (4), 6-9. DOI: 10.7666/d.y164423310.3969/j.issn.1006-9631.2004.04.004

Zhang, X. H., Liu, F., Chen, S., and Qi, G. R. (2007). "Novel flame retardant thermosets from nitrogen-containing and phosphorus-containing epoxy resins cured with dicyandiamide," Journal of Applied Polymer Science 106(4), 2391-2397. DOI: 10.1002/app.26698

Zhang, Y. M., Jiang, J. M., and Chen, Y. M. (1999). "Synthesis and antimicrobial activity of polymeric guanidine and biguanidine salts," Polymer 40(22), 6189-6198. DOI: 10.1016/S0032-3861(98)00828-3

Zhou, H., Liu, Z., and Wei, Y. (2009). "Study on preparation of flame retardant paper by using magnesium hydroxide as flame retardant," Journal of China Pulp \& Paper 28(1), 13-16. DOI: 10.3969/j.issn.0254-508X.2009.01.003

Article submitted: April 14, 2019; Peer review completed: July 28, 2019; Revised version received and accepted: September 6, 2019; Published: September 12, 2019.

DOI: $10.15376 /$ biores. 14.4.8499-8510 